\title{
A TBX5 NONSENSE MUTATION IN SIBLINGS WITH DIVERGENT PHENOTYPES ASSOCIATED WITH ISOLATED SEPTAL DEFECTS
}

\author{
YASHVANTHI BORKAR ${ }^{1}$, KRISHNANANDA NAYAK ${ }^{2}$, RANJAN SHETTY $\mathrm{K}^{3}$, RAJASEKHAR MOKA ${ }^{1 *}$ \\ ${ }^{1}$ Department of Cell and Molecular Biology, School of Life Sciences, Manipal University, Manipal, Karnataka, India. ${ }^{2}$ Department of \\ Cardiovascular Technology, School of Allied Health Sciences, Manipal University, Manipal, Karnataka, India. ${ }^{3}$ Department of Cardiology, \\ Kasturba Medical College, Manipal University, Manipal, Karnataka, India. \\ Email: rsmoka@gmail.com
}

Received: 04 May 2017, Revised and Accepted: 25 May 2017

\section{ABSTRACT}

Objective: Heart septal defects (HSD) account for $50 \%$ of the congenital heart malformations and are characterized by the hole in the wall of tissue which separates the heart chambers. The known causes of the SD are multifactorial and complex inheritance.

Methods: Isolated 15 subjects with ostium secundum atrial SD (OS-ASD) and one subject with perimembranous ventricular SD (VSD) among 125 clinically diagnosed SD were included in the study. Sanger sequencing was performed for all the exons of TBX5 genes using genomic DNA of these patients.

Results: Sequence variation c.444 G>A substitution, leads to the alteration of tryptophan residue into premature stop codon at codon 148 . We observed a divergent phenotype within a family of four, where one sibling and the mother had OS-ASD, another sibling had phenotype of perimembranous VSD, and the father had normal genotype.

Conclusion: We believe that this novel sequence variant in TBX5 gene is one of the factors in the SD and may hold a key determining the role of TBX5 gene in the heart development.

Keywords: T-box gene, TBX5, Septal defect, Gene variant, Transcription factor, DNA sequencing.

(C) 2017 The Authors. Published by Innovare Academic Sciences Pvt Ltd. This is an open access article under the CC BY license (http://creativecommons. org/licenses/by/4. 0/) DOI: http://dx.doi.org/10.22159/ajpcr.2017.v10i9.19628

\section{INTRODUCTION}

Human heart is a 4-chambered organ with each chamber having an important role in storing and pumping the blood flow to and from specific body regions. The structure responsible for this separation is called cardiac septum. The septum is a wall of tissue between left and right heart's structure. A hole in this tissue wall is broadly termed as heart septal defect (HSD), and this defect leads to abnormal blood flow, thereby, reducing the heart's efficiency. HSD are the most common structural cardiac malformations affecting approximately $1 \%$ of live-born and accounts for $50 \%$ of congenital heart defects (CHDs). Various epidemiological studies have demonstrated that CHDs have a genetic predisposition as observed in most of the cases $[1,2]$. Especially, transcription factor genes, primarily NKX2-5, GATA4, and TBX5 have been implicated in regulating the septal development during prenatal stages [3]. The transcriptional genes synergistically influence each other in a complex pathway in the heart development, including the septal formation [4]. Mutation or changes in these genes disrupt the interactions and could lead to the cause of HSD [5].

TBX5 belongs to a phylogenetic family of genes sharing a common DNA binding domain, T-box [6]. Being a transcriptional activator, this gene plays a major role in the development of heart especially differentiation of mesoderm as well as formation and specification of the upper limb identity [7]. Mutation in TBX5 is known to cause Holt-Oram syndrome (HOS) and associated cardiac malformations mainly atrial and ventricular SD (VSD) $[8,9]$. Among the known associated factors for CHDs, about 3-5\% cases are attributed to following the Mendelian Inheritance, and the known association with the HOS [10] provides the required evidence in support of this. However, the etiology of isolated SD in these cases is poorly understood. In view of that, we analyzed
DNA from 125 patients with SD and further sequenced the exon regions of TBX5 gene, to find out the novel variant.

\section{METHODS}

\section{Clinical details of the patients}

Patients were recruited at Cardiology Department, Kasturba Hospital, Manipal, for the study from June 2012 to December 2015, after obtaining written consent. The cardiac complications were examined by the cardiologist and subsequently confirmed using echocardiography. We also included the patient's parents and investigated the cases for assessing the familial history. The study was approved by Institutional Ethical Committee.

\section{Mutational analysis}

Genomic DNA was extracted from the peripheral blood of 125 patients. The whole exons and partial flanking introns of TBX5 gene were amplified by polymerase chain reaction (PCR) in a $25 \mu$ master mix containing $10 \times$ PCR buffer, $10 \mathrm{pmol} / \mu \mathrm{l}$ of forward and reverse primers, $1.5 \mathrm{mmol} / \mathrm{L}$ $\mathrm{MgCl} 2,4 \%$ dimethyl sulfoxide, 4 mmol dNTPs, Taq DNA polymerase ( 5 units/ml, Takara), and $100 \mathrm{ng}$ template DNA. The program for the thermal cycling was set as initial denaturation at $94^{\circ} \mathrm{C}$ for 5 minutes followed by 35 cycles of denaturation for 45 seconds; subsequent annealing for exon 1 , exon 2 , exon 5 at $61^{\circ} \mathrm{C}$, for exon 3 , exon 4 , exon 7 at $59^{\circ} \mathrm{C}$ and for exon 6 and exon 9 at $65^{\circ} \mathrm{C}$ for 30 seconds each and $72^{\circ} \mathrm{C}$ for 45 seconds followed by a final extension at $72^{\circ} \mathrm{C}$ for 10 minutes. The primer sequence of TBX5 gene is represented in Table 1.

The PCR products were then sequenced by the BigDye Terminator ABI Prism Sequencing kit (Applied Biosystems, Foster City, CA, USA), and run on ABI 3130 XL sequencer. Sequencing was carried out twice to confirm the variant using both forward and reverse primers. 
In silico analysis of the variant

Acquired sequences were compared with the reference sequence (NM_000192.3) using BLAT [11]. The observed variations were confirmed using bioinformatics tools such as UCSC genome browser [12], mutation taster [13], PANTHER [14], human genome mutation database [15], and 1000 genome database [16]. Relevant literature was reviewed to check the novelty of the obtained sequence variant. Multiple sequence alignment was carried out using ConSurf [17] whereas, structural analysis and the visualization of protein was also carried out using Protein Data Bank (PDB) file - 4 s0H [18]

\section{RESULTS}

\section{Clinical features}

Out of 125 study subjects with SD, 102 were ostium secundum atrial SD (OS-ASD), 9 were sinus venosus ASD, 12 were perimembranous VSD, 1 was muscular VSD, and 1 was atrio VSD patient. Analysis of the data indicated that 16 out of 125 subjects are heterozygous for a nonsense variant in c.444G>A (p. W148X) leading to premature termination of TBX5 protein in the center of T-box domain. These 16 subjects included in this study, were ascertained through echocardiography and transoesophageal echocardiography (Fig. 1). The gender ratio of the recruited subjects was 1:1, with the mean septum size $19 \mathrm{~mm}$ (4-30 mm). In this study, the patients were screened for TBX5 gene variation. In 15 cases, we observed that all the subjects exhibited OSASD. Surprisingly, sister of a female proband showed a clinical picture of divergent phenotype, perimembranous VSD which was confirmed later. The family of this proband was further investigated with prior consent where the mother too showed OS-ASD phenotype during the imaging study, and the father was normal. The pedigree of the family with the inheritance of isolated SD is represented in Fig. 2a.
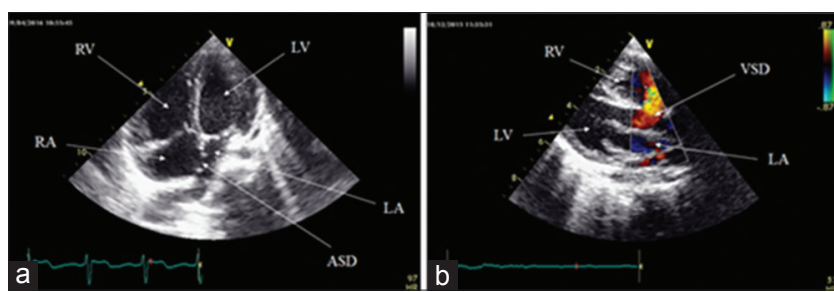

Fig. 1: Echocardiography of the patients showing heart septal defects (SD). (a) Apical four chamber view 2DE showing ostium secundum atrial SD, (b) Plax view- perimembranous VSD, color flow imaging showing left to right shunt
Mutational analysis

DNA samples of both parents and the sibling were subjected to molecular analysis, DNA sequencing of PCR-amplified exon 5 of TBX5. Mother was heterozygous to TBX5, c.444G>A and the father was normal. This variant was also found de novo in 13 sporadic cases with the similar clinical phenotype of OS-ASD. This novel heterozygous variant,

Table 1: List of PCR primers of TBX5 gene and the product size

\begin{tabular}{|c|c|c|}
\hline Exons & Primers & $\begin{array}{l}\text { Amplicon } \\
\text { size (bp) }\end{array}$ \\
\hline E1P1 & $\begin{array}{l}\text { FP: GGTATTCATTTGCCCAGAGC } \\
\text { RP: CCCAGTAAAATAAAGAGGCAACC }\end{array}$ & 478 \\
\hline E1P2 & $\begin{array}{l}\text { FP: CCAGCCAAACGTGACAGC } \\
\text { RP: GCCAAGTGCAAAGAGAAACC }\end{array}$ & 390 \\
\hline E2 & $\begin{array}{l}\text { FP: TTTCTCTCGTTCTCTCTCTGTCC } \\
\text { RP: CAGACTCTGACTTTGATCTCTGC }\end{array}$ & 297 \\
\hline E3 & $\begin{array}{l}\text { FP: GTGTTTTGGGGGAGTTTGG } \\
\text { RP: GCCACCTTTTCTTCTTCACC }\end{array}$ & 243 \\
\hline E4 & $\begin{array}{l}\text { FP: GAGGCTGCCTTAAAATACTGG } \\
\text { RP: AACTTTTTGGGAGAAGGTTCC }\end{array}$ & 248 \\
\hline E5 & $\begin{array}{l}\text { FP: CTGGTGCGTGAACTGAAGC } \\
\text { RP: GAGGACAAGAGGGAGACAAGG }\end{array}$ & 282 \\
\hline E6 & $\begin{array}{l}\text { FP: GGGAGCAGGGTTTTATCTGG } \\
\text { RP: TGCAAAAGAAAGAGCAGACG }\end{array}$ & 280 \\
\hline E7 & $\begin{array}{l}\text { FP: TGGCTTAATTTGCTTCTTTTGG } \\
\text { RP: GGTTGCTGCTGGCTTACC }\end{array}$ & 294 \\
\hline E8 & $\begin{array}{l}\text { FP: TCTCTCACACCTGGTTCAGC } \\
\text { RP: ATACTCCTCACCCССTCACC }\end{array}$ & 390 \\
\hline E9P1 & $\begin{array}{l}\text { FP: TTGGCCAAATAACTGTCTCC } \\
\text { RP: GCTGGAACATTCCCTCTCC }\end{array}$ & 465 \\
\hline E9P2 & $\begin{array}{l}\text { FP: ACTTCTCCGCTCACTTCACC } \\
\text { RP: TTTTTAAAATTGTGGTTTCAAGC }\end{array}$ & 474 \\
\hline E9P3 & $\begin{array}{l}\text { FP: GGACAAGATTTTTCATTTCACC } \\
\text { RP: GGTAGGTGCTTTTCTTAGTCAAGG }\end{array}$ & 496 \\
\hline E9P4 & $\begin{array}{l}\text { FP: GGACCCAGTCCCTTATTTGG } \\
\text { RP: TGGGTTGTTGGTGATGGAGG }\end{array}$ & 545 \\
\hline E9P5 & $\begin{array}{l}\text { FP: TGGCCTATAGCTTCCCTTCC } \\
\text { RP: CTCTTGGCCAGCTCCTATGC }\end{array}$ & 482 \\
\hline E9P6 & $\begin{array}{l}\text { FP: TGTGTAAGTAAAGTGTTATGGTAGG } \\
\text { RP: AAAGAGACATAATCGCATAGGG }\end{array}$ & 361 \\
\hline E9P7 & $\begin{array}{l}\text { FP: AAGAGAACAGGGTAAGATGTGAGG } \\
\text { RP: TTCCTGTTTCCTCCAATTCC }\end{array}$ & 276 \\
\hline
\end{tabular}

The primer sequences are acquired from Granados-Riveron et al. 2012. FP: Forward primer, RP: Reverse primer, E: Exon, and PCR: Polymerase chain reaction

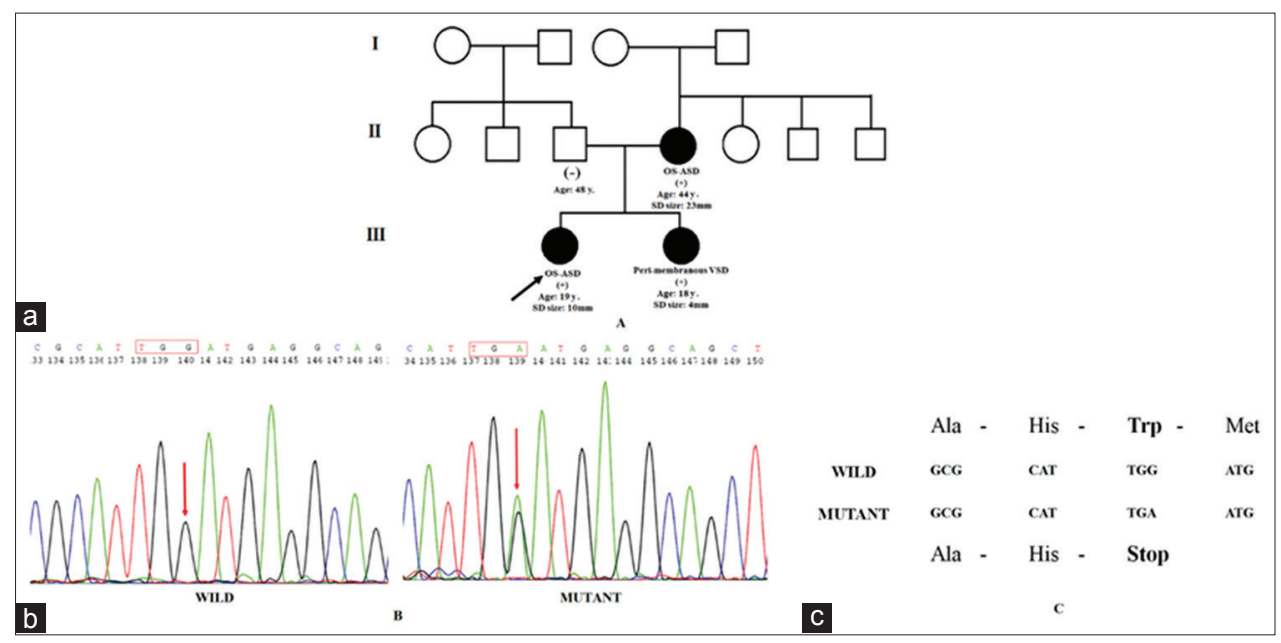

Fig. 2: Identification of a novel TBX5 variant, c.444G>A (p. W148X) associated with the heart septal defects. (a) Pedigree of an Indian family showing inherited TBX5 variant across the generations. Square represents male and circle represents female; arrow indicates the proband, darkened circle represents affected individuals, (b) Sequence analysis of TBX5 exon 5; (1) Affected individual and (2) Normal individual, and (c) Single base pair substitution altering tryptophan to stop (W148X) 


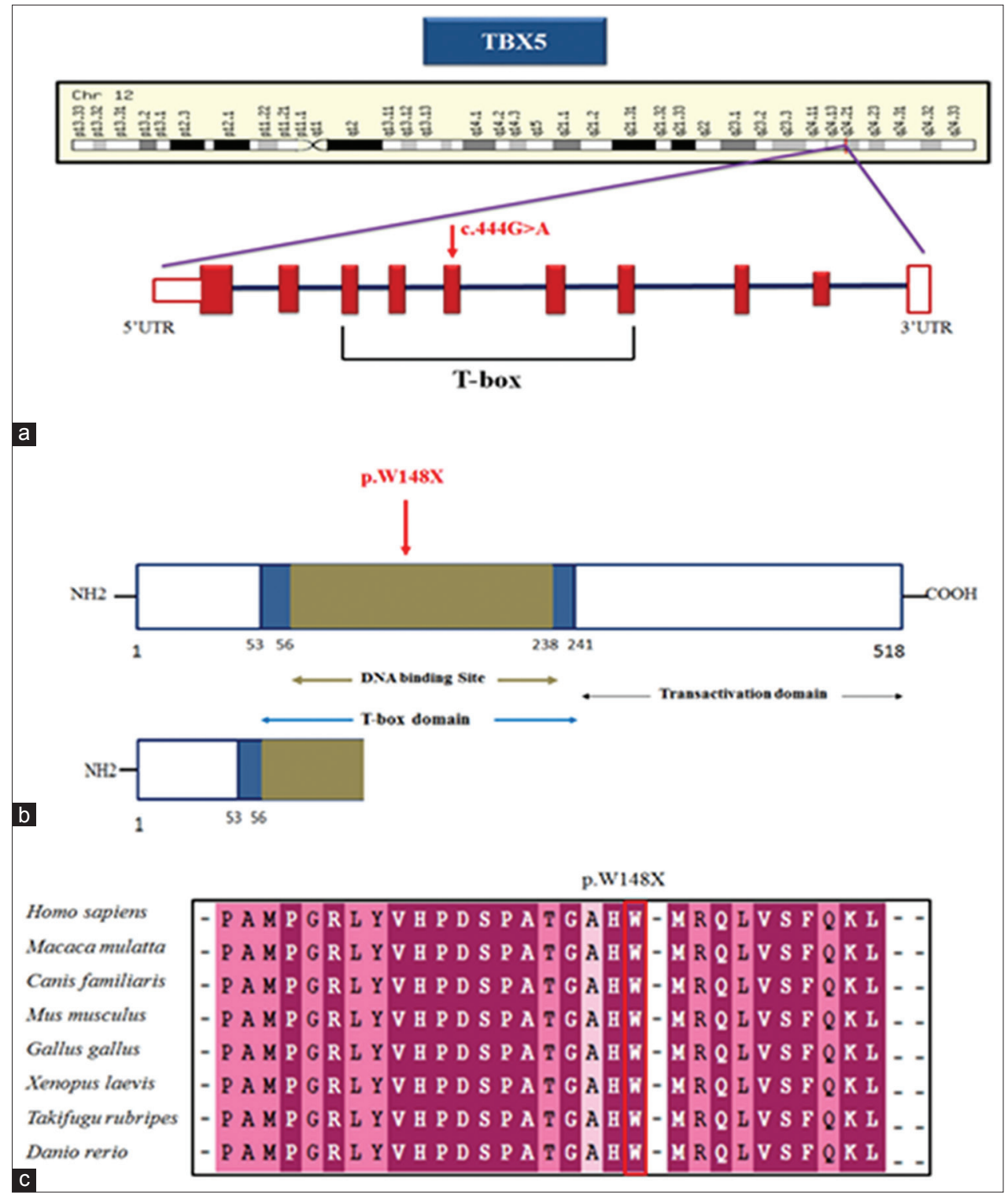

Fig. 3: Schematic representation showing genomic and proteomic organization of TBX5 gene. (a) Structure of TBX5 gene indicating the substitution from $G \rightarrow A$ at exon 5 , (b) Wild-type TBX5 protein and premature termination due to stop codon resulting in truncated TBX5, and (c) Cross-species alignment showing the evolutionary conservation of the mutated residue by ConSurf analysis

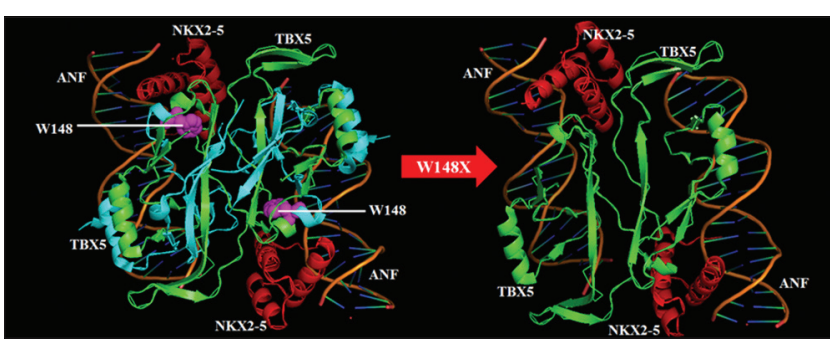

Fig. 4: Molecular modeling of two asymmetric ternary complexes of ANF-TBX5-NKX2-5 proteins. TBX5 is colored with green and missing residues are shown in cyan, NKX2-5 is colored with red, mapping of W148 is shown in magenta color, DNA backbone is colored brown

c. $444 \mathrm{G}>\mathrm{A}$ substitution, leads to the alteration of tryptophan residue into premature stop codon at codon 148 (p. W148X; TGG $\rightarrow$ TGA), resulting in the truncated protein, represented in the chromatogram (Fig. $2 \mathrm{~b}$ and c). The TBX5 gene represented in Fig. 3a comprises a
T-box domain and a transactivation domain. The novel variant is shown in Fig. 3b. The Wild type tryptophan residue at codon 148 is highly conserved across the species from zebrafish to humans as specified in Fig. 3c, resulting in a truncated protein with 147 amino acids. Crossspecies alignment indicated that the mutated amino acid residue is functionally important suggesting that the variant is possibly damaging the protein structure and function. This nonsense variant results in the absence of the functional and binding domain. Further, protein modeling was done using PyMOL with the help of PDB file $4 \mathrm{~s} 0 \mathrm{H}$, to find out the interaction for ternary complexes of atrial natriuretic factor (ANF)-TBX5-NKX2-5 genes (Fig. 4). We observed that there is a loss of binding capacity to ANF factor because of premature truncation in the TBX5 gene.

\section{DISCUSSION}

CHD are multifactorial as well as heterogeneous in nature [19]. SD are most common cause of CHDs and occur sporadic or familial forms [20,21]. Familial forms may follow atypical patterns of inheritance resulting in variable phenotype, such that TBX5 gene 
mutation c.444G>A; detected in the recruited subjects with SD. In this study, among the HSDs, the OS-ASD forms a significant kind of phenotype. Out of 125 cases subjected to TBX5 exon analysis, we observed a very close association between OS-ASD and TBX5 mutation. In this case, three members of a family shown to have atypical pattern of disease inheritance. The mutation was inherited from the mother to both the children, but the resulting phenotype diverged in these siblings. The reason for this diverse phenotype following the same mutation is still unclear. The cross-species alignment of TBX5 protein showed that the altered tryptophan residue is evolutionarily conserved throughout the vertebrates, indicating its functional importance [22]. The understanding of the genetic mutations is an important aspect in deciphering the consequential clinical phenotypes $[23,24]$. This study was performed to investigate the basis of this divergent phenotype related to a single gene mutation. The genetic study was further analyzed using bioinformatics tools, and the variant was estimated to be disease causing by Mutation Taster and with high probability to be damaging by PANTHER.

For this purpose, we carried out complete comparative protein modeling by PyMol, to locate this novel variant, which may have an impact on DNA binding domain and the dimerization interface. DNA binding domains of NKX2-5 (138-197 amino acid residues of homeodomain) and TBX5 (58-239 amino acid residues of T-box domain) forms a complex and binds to specific DNA motif. This infers that the DNA binding domains of these genes are essential for functional and physical interactions as well as for synergistic activation of other transcription factors. The interaction between TBX5-CRM1 has been documented, whereby, mutations in TBX5 affects the relocation [25]. The variant, c. $444 \mathrm{G}>\mathrm{A}$ is found to be located at $\alpha$-helix 2 sites. Further, $\alpha$-helix 3 and $3_{10}$-helix C play a crucial role as DNA recognition elements by binding to DNA. The premature stop codon at position 148 , leads to a probable loss in the interaction of TBX5 with CRM1 and binding of ANF-252 DNA [26]. Hence, this variant can be considered as hot spot mutation in the TBX5 gene and to be associated with isolated and nonsyndromic SD. However, the results of this study can further be characterized to explore the functional mechanisms leading to the heart septal development.

A truncation mutation p. Glu69Ter was identified in the exon 3 of TBX5, in the affected family members with dominant phenotype, HOS. This truncating mutation is a transversion from $\mathrm{G} \rightarrow \mathrm{T}$ that converts GAA (glutamate residue) to TAA (stop codon). Hence, this mutation results in the haploinsufficiency in patients with HOS suggesting that HOS are caused by mutation in TBX5 [27]. Another study reported a novel mutation in the exon 5 of TBX5, p. Y136X. This mutation was identified in the members of two unrelated families having HOS [28]. A novel nonsense mutation in the exon 3 of TBX5 associated with single HOS patient, $192 \mathrm{G}>\mathrm{A}$ (p. W64X) results in the truncation of TBX5 polypeptide by $88 \%$. Here, the substitution happens at the $2^{\text {nd }}$ position of codon 64 where tryptophan residue changes into stop codon and is located at the T-box domain [29]. A study demonstrated that expressivity of malformation in patients with HOS cannot be predicted by either by the location of the mutation in the T-box domain or the TBX5 mutation [30]. However, in our study, the affected individuals with nonsense variant are devoid of any HOS phenotype.

\section{CONCLUSION}

We report for the first time a novel nonsense variant in an Indian family with different phenotype and this variant is de novo in 13 sporadic cases without any limb deformities. This study aids in expanding the mutation spectrum of TBX5 in the Indian population and provides a new insight into understanding the molecular mechanism of TBX5 mutation underpinning OS-ASD.

\section{ACKNOWLEDGMENTS}

The authors thank the patients and their parents for their active participation in the study. We are grateful to the Department of Cardiology, Kasturba Hospital, Manipal, India, for providing the blood samples of the patients with HSD. Furthermore, thank Manipal University and School of Life Sciences for providing the infrastructure and supporting this work. This study was financially supported by Indian Council of Medical Research, New Delhi, India.

\section{REFERENCES}

1. Pierpont ME, Basson CT, Benson DW Jr, Gelb BD, Giglia TM, Goldmuntz E, et al. American heart association congenital cardiac defects committee, council on cardiovascular disease in the young. Genetic basis for congenital heart defects: Current knowledge: A scientific statement from the American heart association congenital cardiac defects committee, council on cardiovascular disease in the young: Endorsed by the American academy of pediatrics. Circulation 2007; 115:3015-38

2. Gelb BD, Chung WK. Complex genetics and the etiology of human congenital heart disease. Cold Spring Harb Perspect Med 2014;4(7):a013953.

3. McCulley DJ, Black BL. Transcription factor pathways and congenital heart disease. Curr Top Dev Biol 2012;100:253-77.

4. Granados-Riveron JT, Pope M, Bu'lock FA, Thornborough C, Eason J, Setchfield K, et al. Combined mutation screening of NKX2-5, GATA4, and TBX5 in congenital heart disease: Multiple heterozygosity and novel mutations. Congenit Heart Dis 2012;7(2):151-9.

5. Hiroi Y, Kudoh S, Monzen K, Ikeda Y, Yazaki Y, Nagai R, et al. Tbx5 associates with Nkx2-5 and synergistically promotes cardiomyocyte differentiation. Nat Genet 2001;28(3):276-80.

6. Ghosh TK, Packham EA, Bonser AJ, Robinson TE, Cross SJ, Brook JD. Characterization of the TBX5 binding site and analysis of mutations that cause Holt-Oram syndrome. Hum Mol Genet 2001;10(18):1983-94.

7. Basson CT, Huang $\mathrm{T}$, Lin RC, Bachinsky DR, Weremowicz S, Vaglio A, et al. Different TBX5 interactions in heart and limb defined by Holt-Oram syndrome mutations. Proc Natl Acad Sci U S A 1999;96(6):2919-24.

8. Borozdin W, Bravo Ferrer Acosta AM, Bamshad MJ, Botzenhart EM, Froster UG, Lemke J, et al. Expanding the spectrum of TBX5 mutations in Holt-Oram syndrome: Detection of two intragenic deletions by quantitative real time PCR, and report of eight novel point mutations. Hum Mutat 2006;27(9):975-6.

9. Guo Q, Shen J, Liu Y, Pu T, Sun K, Chen S. Exome sequencing identifies a c.148-1G $>$ C mutation of TBX5 in a Holt-Oram family with unusual genotype-phenotype correlations. Cell Physiol Biochem 2015;37(3):1066-74

10. van der Bom T, Zomer AC, Zwinderman AH, Meijboom FJ, Bouma BJ, Mulder BJ. The changing epidemiology of congenital heart disease. Nat Rev Cardiol 2011;8(1):50-60.

11. Kent WJ. BLAT-the BLAST-like alignment tool. Genome Res 2002;12:656-64.

12. Kent WJ, Sugnet CW, Furey TS, Roskin KM, Pringle TH, Zahler AM, et al. The human genome browser at UCSC. Genome Res 2002;12:996-1006.

13. Schwarz JM, Rödelsperger C, Schuelke M, Seelow D. MutationTaster evaluates disease-causing potential of sequence alterations. Nat Methods 2010;7(8):575-6

14. Mi H, Poudel S, Muruganujan A, Casagrande JT, Thomas PD. PANTHER version 10: Expanded protein families and functions, and analysis tools. Nucleic Acids Res 2016;44:D336-42.

15. Stenson PD, Ball EV, Mort M, Phillips AD, Shiel JA, Thomas NS, et al. Human gene mutation database (HGMD): 2003 update. Hum Mutat 2003;21(6):577-81.

16. Genomes Project Consortium, Abecasis GR, Altshuler D, Auton A, Brooks LD, Durbin RM, et al. A map of human genome variation from population-scale sequencing. Nature 2010;467(7319):1061-73.

17. Ashkenazy H, Erez E, Martz E, Pupko T, Ben-Tal N. ConSurf 2010: Calculating evolutionary conservation in sequence and structure of proteins and nucleic acids. Nucleic Acids Res 2010;38:W529-33.

18. Pradhan L, Gopal S, Li S, Ashur S, Suryanarayanan S, Kasahara H, et al. Intermolecular interactions of cardiac transcription factors NKX2.5 and TBX5. Biochemistry 2016;55(12):1702-10.

19. Richards AA, Garg V. Genetics of congenital heart disease. Curr Cardiol Rev 2010;6:91-7.

20. Posch MG, Gramlich M, Sunde M, Schmitt KR, Lee SH, Richter S, et al. A gain-of-function TBX20 mutation causes congenital atrial septal defects, patent foramen ovale and cardiac valve defects. J Med Genet 2010;47(4):230-5

21. Bidkar JS, Ghanwat DD, Bhujbal MD, Dama GY. Cardiotonic activity 
of portulaca oleracea on isolated frog heart. Int J Pharm Pharm Sci 2011;3:118-20.

22. Wang ZC, Ji WH, Ruan CW, Liu XY, Qiu XB, Yuan F, et al. Prevalence and spectrum of TBX5 mutation in patients with lone atrial fibrillation. Int J Med Sci 2016;13(1):60-7.

23. Ching YH, Ghosh TK, Cross SJ, Packham EA, Honeyman L, Loughna S, et al. Mutation in myosin heavy chain 6 causes atrial septal defect. Nat Genet 2005;37:423-8

24. Shetty K, Shetty R, Rao P, Vivek G, Naveenchandra GS, Razak A, et al. Evaluation of causative factors in amlodipine induced pedal edema. Int J Pharm Pharm Sci 2016;8:303-6.

25. Kulisz A, Simon HG. An evolutionarily conserved nuclear export signal facilities cytoplasmic localization of the Tbx 5 transcription. Mol Cell Biol 2008;28:1553-64

26. Stirnimann CU, Ptchelkine D, Grimm C, Müller CW. Structural basis of TBX5-DNA recognition: The T-box domain in its DNA-bound and -unbound form. J Mol Biol 2010;400(1):71-81.

27. Basson CT, Bachinsky DR, Lin RC, Levi T, Elkins JA, Soults J, et al. Mutations in human TBX5 [corrected] cause limb and cardiac malformation in Holt-Oram syndrome. Nat Genet 1997;15(1):30-5.

28. Gruenauer-Kloevekorn C, Froster UG. Holt-Oram syndrome: A new mutation in the TBX5 gene in two unrelated families. Ann Genet 2003;46(1):19-23

29. Fan C, Duhagon MA, Oberti C, Chen S, Hiroi Y, Komuro I, et al. Novel TBX5 mutations and molecular mechanism for Holt-Oram syndrome. J Med Genet 2003;40(3):e29.

30. Brassington AM, Sung SS, Toydemir RM, Le T, Roeder AD, Rutherford AE, et al. Expressivity of Holt-Oram syndrome is not predicted by TBX5 genotype. Am J Hum Genet 2003;73(1):74-85. 